\title{
Harmonic Minimization in a Modified Cascaded Multilevel Inverter for Islanded Microgrid using two Switching Techniques
}

\author{
Mamatha Sandhu and Tilak Thakur \\ Chitkara university, Punjab Campus, PEC University of Technology, \\ Chandigarh, India \\ mamatha.sandhu@chitkara.edu.in,tilak20042005@yahoo.co.in
}

\begin{abstract}
Renewable energy sources are playing very wide role for their abundant availability. Photovoltaic systems are widely used for their cleanliness and less maintenance. Multilevel inverter technology has become an emerging technology with renewable energy sources and are playing a wide role in designing various topologies. In this paper, an islanded microgrid from a remote area fed from solar PV system through a modified topology of 7 level 6 switches cascaded H bridge multilevel inverter using two different switching tecniques are presented. A solar photovoltaic $(P V)$ system and an energy storage is fed through DC-DC boost converter which is equipped with incremental conductance maximum power point tracking (MPPT) algorithm to extract maximum solar energy is considred in the islanded microgrid. A comparison of Sinusoidal Pulse Width Modulation (SPWM) using Particle Swarm Optimization (PSO) and Artificial Neural Network (ANN) switching techniques which leads to the improvement of total harmonic distortion (THD) for power quality applications is carried out. Due to modified topology reductions in the number of power switches, losses are obtained. To verify the performance of the switching techniques simulations are carried out using MATLAB/SIMULINK and the total harmonic distortion is calculated.
\end{abstract}

Keywords: $P V, S P W M, C H B M L I, M P P T, A N N, P S O, T H D$

\section{Introuction}

Ever increasing in the energy demand, fossil fuels exhausting nature and growing prices, environmental problems caused like $\mathrm{CO}_{2}$ emissions from conventional power plants have made more research to be carried out on renewable energy based distributed power generation systems. Various renewable energy sources are available among them the wind and photovoltaic are very promising and popular around the globe. Microgrid can be framed with intelligent control using both renewable sources wind and solar with energy storage. These type of microgrids at a remote location can help to depend less on the power grids. Microgrid fed from renewable energy resources is discussed in [1-3]. These papers are not including the performance of system parameters such as power quality, efficiency of the system, under various operating conditions. The place is very much important for the availability of the renewable resources for continuous generation of electricity supply. It is very much required that the system must be used at optimum point to harness maximum energy and in turn reduce the cost price. Multilevel inverters are attracting the industries due to their ability to produce smooth sinusoidal output voltage waveforms with lower switching frequency. It has spread in the research areas for studying higher voltages and power applications [4] due to the lower switching losses, higher effciecncy and EMI inference. Multilevel inverters are available for both high switching and low switching configurations. With high switching means lower efficiency

Received (August 16, 2017), Review Result (November 16, 2017), Accepted (November 30, 2017) 
and higher switching loses and low switching frequency means higher efficiency and low switching losses as seen in the literature work. In this paper, in order to generate the switching signals for the multilevel inverter a sinusoidal pulse-width modulation (SPWM) technique is implemented using Particle Swarm Optimization (PSO) PID and Artificial Neural Network (ANN) techniques.

This paper presents two different switching techniques which compares the improvement in the total harmonic distortion and also can be seen that maximum power point technique improves the THD along with these techniques. The paper is divided in five sections as Section-II is covered with overall scheme of the system description of components. Section-III is covered with the switching techniques used for the multilevel inverter of the microgrid. Section-IV presents the simulation diagram of the microgrid for all the switching techniques simulated using MATLAB/SIMULINK. Section -V presents result analysis of the above models.

\section{Design of the Overall Sytem of Islanded Microgrid}

The photovoltaic system converts the light energy of sun intoelectrical energy with the help of solar stages. The generatedelectricity is in direct current (DC) form. An energy storage battery is used for continuous power supply. A DC-DC boost converter is connected to the solar PV system along with battery storage and is equipped with maximum power point tracking (MPPT) - Incremental Conductance algorithm for extracting maximum energy. In [5], maximum power point (MPP) changes continuously because of continuous changes in the irradiance level of the sun, $\mathrm{P} \& \mathrm{O}$ takes a wrong calculation due to perturbation, but Incremental Conductance improves due to the samples taken for voltage and current for MPP calculation. With the multilevel inverters the harmonic distortions can be reduced with the increase in the higher levels of output. With separate dc sources the cascaded multilevel inverters are used [13], in our research a modified topolopgy of 7 level 6 switches cascaded multilevel invereter [7] is used. Switching power devices causes harmonics in the sensitive equipments which are connected to the non-linear loads for the applications of higher kilowatts, hence an LCLfilter is connected at the output of modified multilevel inverter to reduce the total harmonic distortion (THD) in the islanded microgrid as shown in the block diagram of Figure 1 below [1]. An LCL filter is used in the circuit due to good attenuation capacity for higher-order harmonics and dynamic characteristics [6].

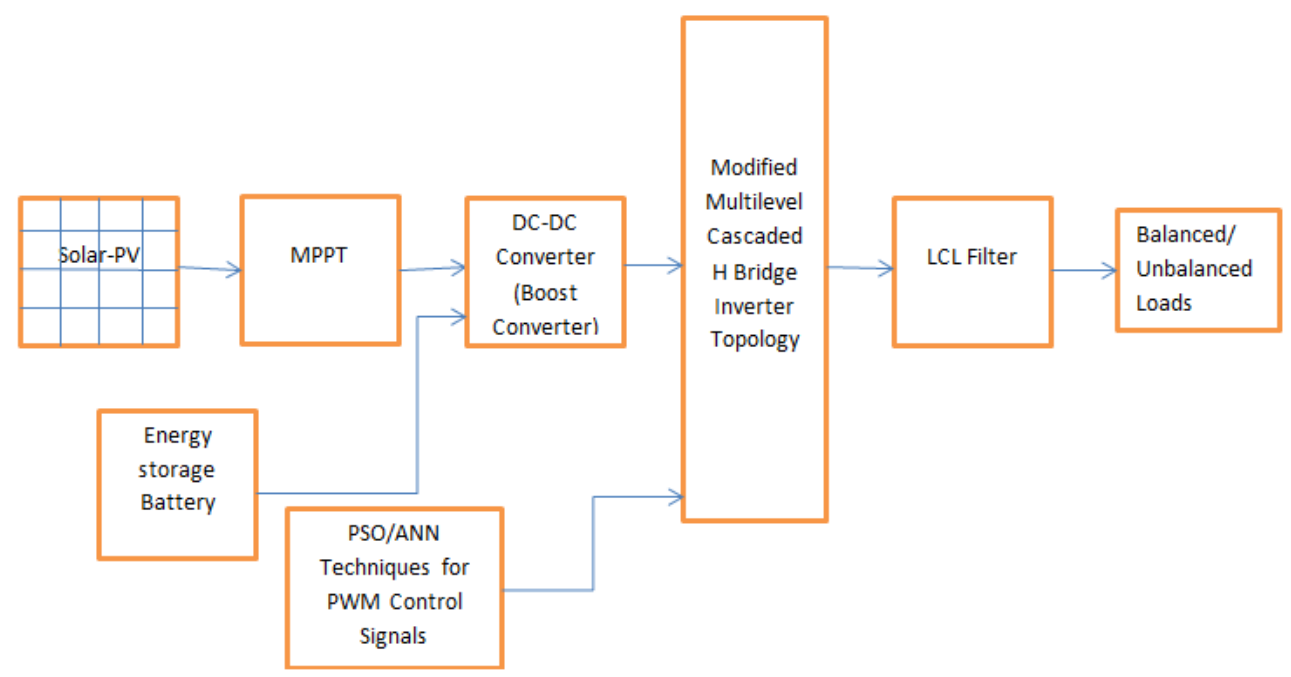

Figure 1. Schematic Diagram of Islanded Microgrid Network Fed By Renewable Energy Source (PV) 


\subsection{Modified Cascaded H Bridge Multilevel Inverter (CHBMLI)}

A modified topology of 7-level 6 switches inverter as shown in Figure 2. chooses suitable sinusoidal modulation technique as the power circuits [10]. The output voltage has seven levels: zero, positive $(+\mathrm{Vdc},+2 \mathrm{Vdc},+3 \mathrm{Vdc}$,) and negative ( $-\mathrm{Vdc},-2 \mathrm{Vdc},-$ $3 \mathrm{Vdc}$,) supply dc voltage, $\mathrm{Vdc}$ as the supply voltage. By comparing the carrier frequency and switching functions, the harmonic components of the output voltage are calculated.

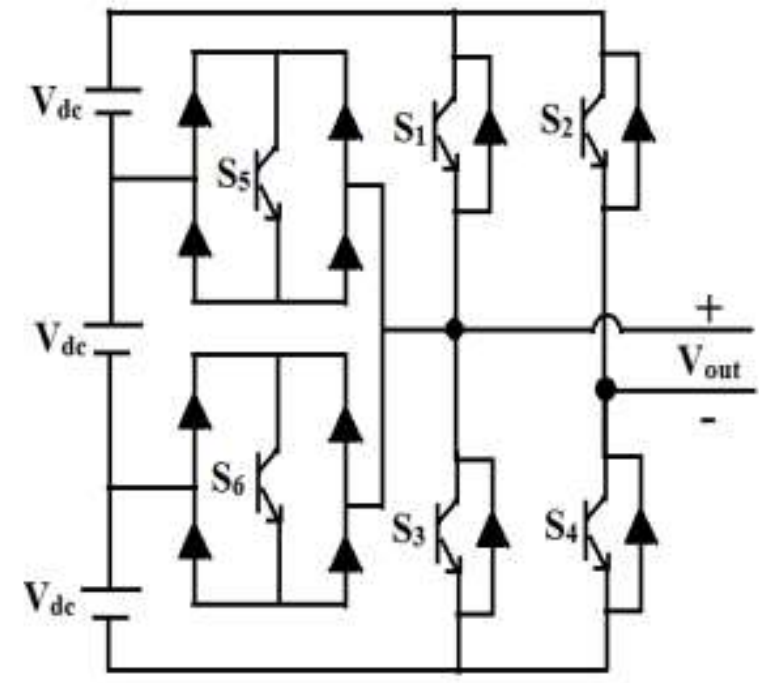

Figure 2. Modified 7 Level 6 Switches Topology [10]

\section{Sinusoidal Pulse Width Modulation (SPWM) Switching Techniques}

In order to digitize the power widely used in power electronics sinusoidal pulse width modulation generates the sequence of pulses of voltage by switching on and off the power switches. SPWM technique is mainly used in industrial applications. Here, constant amplitude pulses with various duty cycle for every period is considered. Modulation of the width is carried out to acquire the output voltage control there by reducing its harmonic contents. Most commonly used the Sinusoidal pulse width modulation or SPWM method is used in motor control and inverter applications [5].

\subsection{Particle Swarm Optimization (PSO) Techniquewith PID controller}

The particle swarm optimization (PSO) is an effective and fastest optimization algorithm to define the optimal solution for the non-linear issues. Each time particles can be created with new values to calculate the approximate solution w.r.t both position and velocity of vectors. In enter search space, position vectors said to be $\mathrm{Yi}=[\mathrm{y} 1, \mathrm{y} 2 \ldots \mathrm{yD}]$ and the velocity vector $\mathrm{Vi}=[\mathrm{v} 1, \mathrm{v} 2, \ldots, \mathrm{vD}]$. As discussed in [8] the flowchart is used for the optimal solution to calculate the switching angles using PID controller.The cascaded H-bridge multilevel inverter with PID controller is shown in [10]. A linear combination of the P, I and D contributions carried out on the error is the PID controlled gate signals which are generated by sinusoidal pulse width modulation technique. The three isolated dc power sources are connected to the cascaded H-bridge seven level inverter. The output of the PID controller is multiplied with the unit reference signal to provide the required modulating signal $(\mathrm{ms})$ and is used to produce the gating pulses in association with a carrier. The output of the cascaded H-bridge 7 level 6 switches inverter is given to the load through LCL filter to obtain sinusoidal output (Vo) and is compared with the reference voltage (Vref) to produce the error signal (e). 


\subsection{Artificial Neural Network (ANN):}

The ANN isused to generate optimal switching angles in which an input neuron is fed by the modulation index, where a single hidden layer and multiple outputs represents a switching angle. To learn the switching patterns; and trained ANN used to estimate the optimum switching angles of inverter are discussed [9]. In the field of power electronics and electric drives section the application of ANN is growing very fastly. In controlling dc-ac inverters for controlling the voltage of inverters for ac motor drives ANNs are being used. Non-linear input-output mapping is implemented in feed forward ANN. Any objective function can be selected for the optimal switching pattern which depends on the desired modulation index.

In the presented paper, an alternative switching angles look -up table to generate the optimum switching angles for multilevel inverters is developed using neural network predictive control simulink library of MATLAB. Multi layered feed forward propagation network is used where the output voltage is controlled continuously with the modulation indexes which helps in not using the memory for look-up table after training the ANN [11].

\section{Matlab/Simulink Simulations}

\subsection{Overall Design Model using PSO-PID Technique}

Modified topolopgy of 7 level 6 switches cascaded multilevel invereter with nonlinear loads and an LCL-filter is connected at the output of modified mulitilevel inverter of islanded microgrid model using MATLALAB/SIMULINK ss shown in the Figure 3 below. PV Solar Voltage :- $\operatorname{Imax}=9 \mathrm{~A}$, Vmax $=1.88 \mathrm{kV}$ DC, Power $=16.92 \mathrm{~kW}$. Battery $=$ $100 \mathrm{Ah}$, Grid output voltage $=173.20 \mathrm{kV}$ AC.

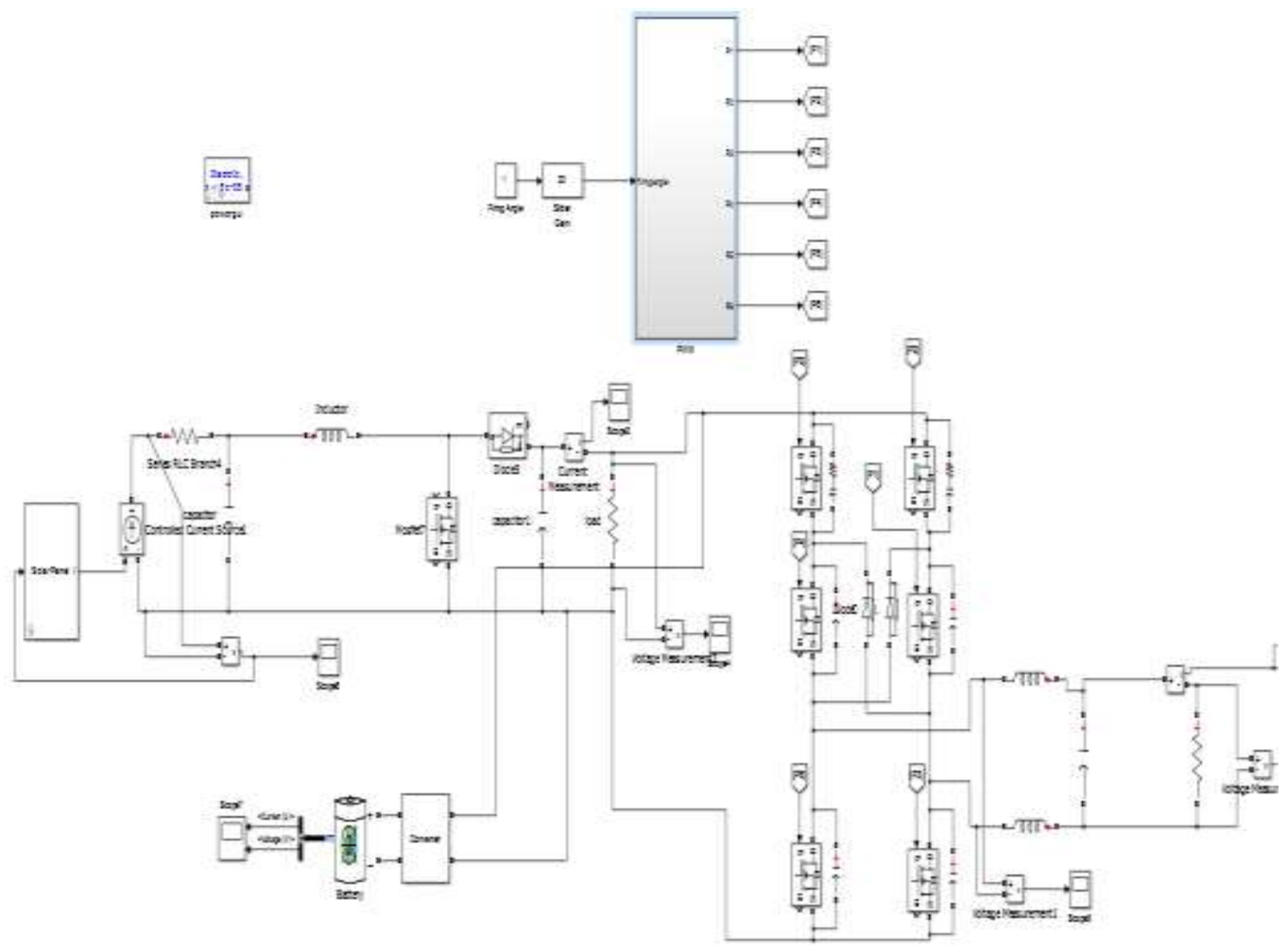

Figure 3. Overall System Design using PSO -PID Technique 


\subsection{PSO-PID Controller}

The input of the PID controller is error e. The designed values of $\mathrm{Kp}, \mathrm{Ki}$ and $\mathrm{Kd}$ are 10, 0 and 1 respectively. This paper chooses the sinusoidal PWM control strategy each pulse width is varied in proportion to the sine wave amplitude determined at the same pulse [10]. Specifications: Type; SPWM Carrier frequency $=3 \mathrm{Khz}$, Operetaing Frequency $=50 \mathrm{~Hz}$, Gain $=\mathrm{K}=6500$ Phase delay $=0$ as shown in Figure 4.

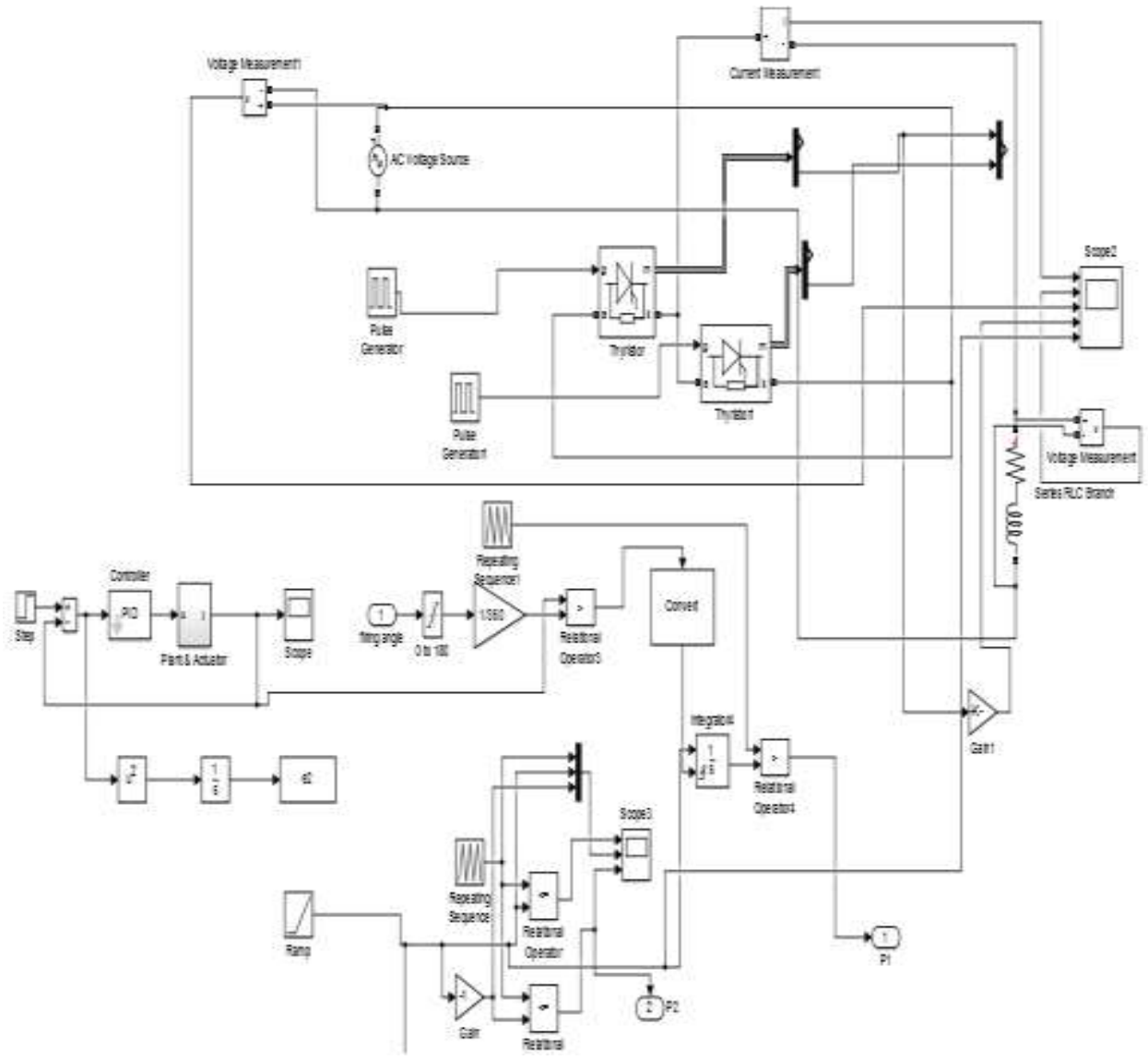

Figure 4. PWM Switching Gate Signals for CHBMLI using PSO-PID

\subsection{Artificial Neural Network (ANN) Matlab/Simulink Model}

The network model is integrated with 7 level 6 switches modified cascaded H Bridge multilevel invereter to generate the switching angles using the MATLAB/SIMULINK. [11] Hidden layers and activation functions which optimize the performance are used for training. Sigmoid activation function is used here. Once the training pulse is terminated, the control sequence of the inverter obtained by ANN is generated. For a given set of input values to the ANN, step wise calculations are carried out in the forward direction to obtain the output pattern. The gradient descent method is used to alter the weights at the starting time from the output layer to generate the mean square error(MSE) for a set of input patterns to be minimized.

PV Solar : Imax $=9 \mathrm{~A}, \mathrm{Vmax}=4.5 \mathrm{kV}$ DC, Power $=40.5 \mathrm{~kW}$, Open circuit voltage $64.2 \mathrm{~V}$, Short circuit current $=5.96$. Grid output Voltage $=216.25 \mathrm{KV}$ AC. 


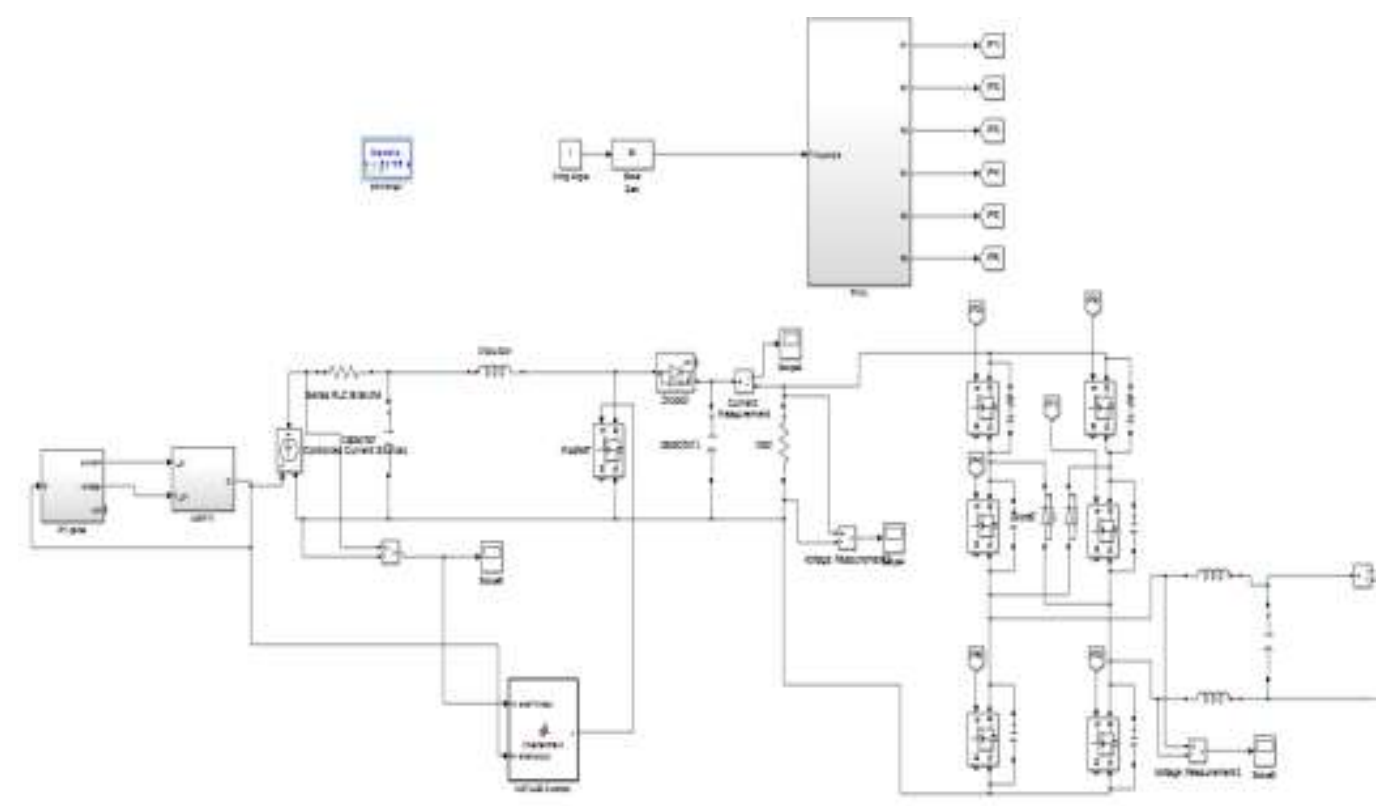

Figure 5.Overall System design of Artificial Neural Network using Matlab/Simulink

\section{Result Analysis of PSO AND ANN Techniques}

\subsection{PSO Technique}

Closed loop response of PID Controller is as shown in Figure 6. and voltage and current measuremts with gain are shown in Figure 7. The output voltage of the microgrid is $216.25 \mathrm{KV} \mathrm{AC}$ as shown in Figure 8. The total harmonic distortion obtained is with the value of $70.29 \%$ as seen in Figure 9 for the Fundamental frequency of $50 \mathrm{~Hz}$.

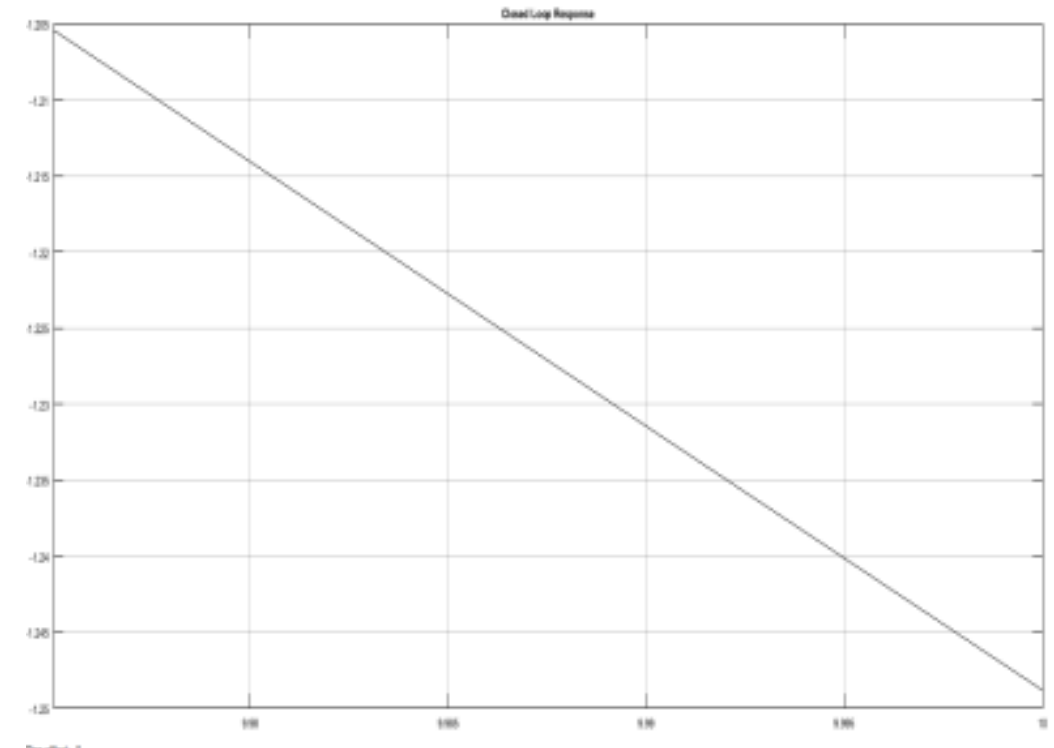

Figure 6. Closed Loop Response of PID Control using PSO Technique 


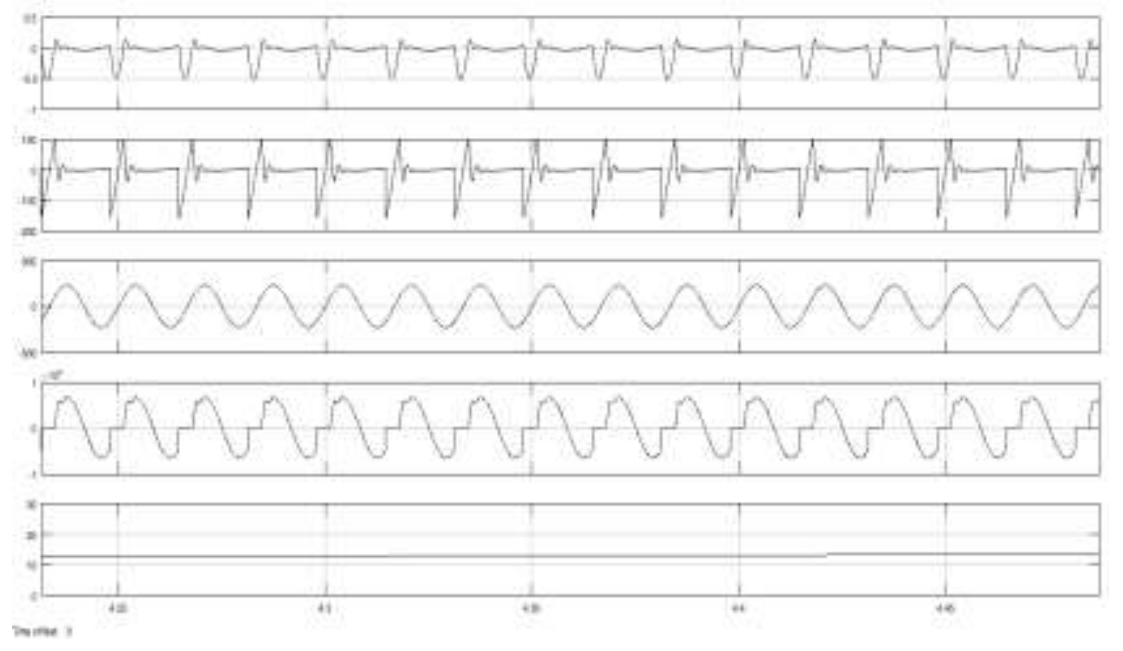

Figure 7. PSO-PID Voltage and Current Mesurements With Gain and Ramp Output

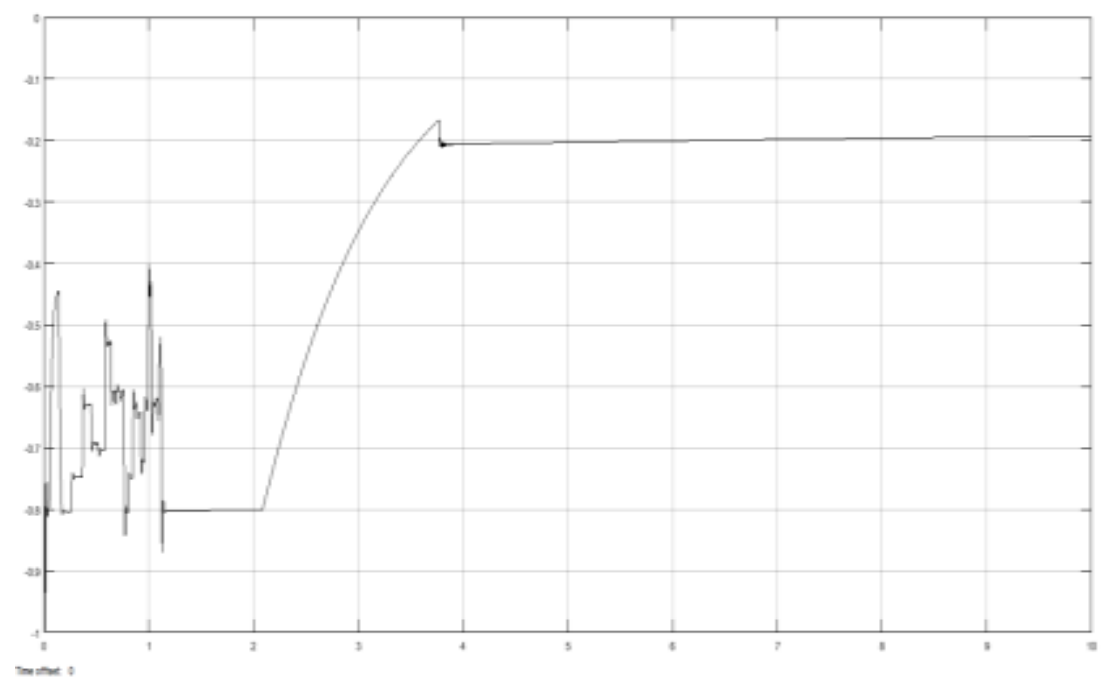

Figure 8. Load Output Voltage using PSO Technique of the Microgrid

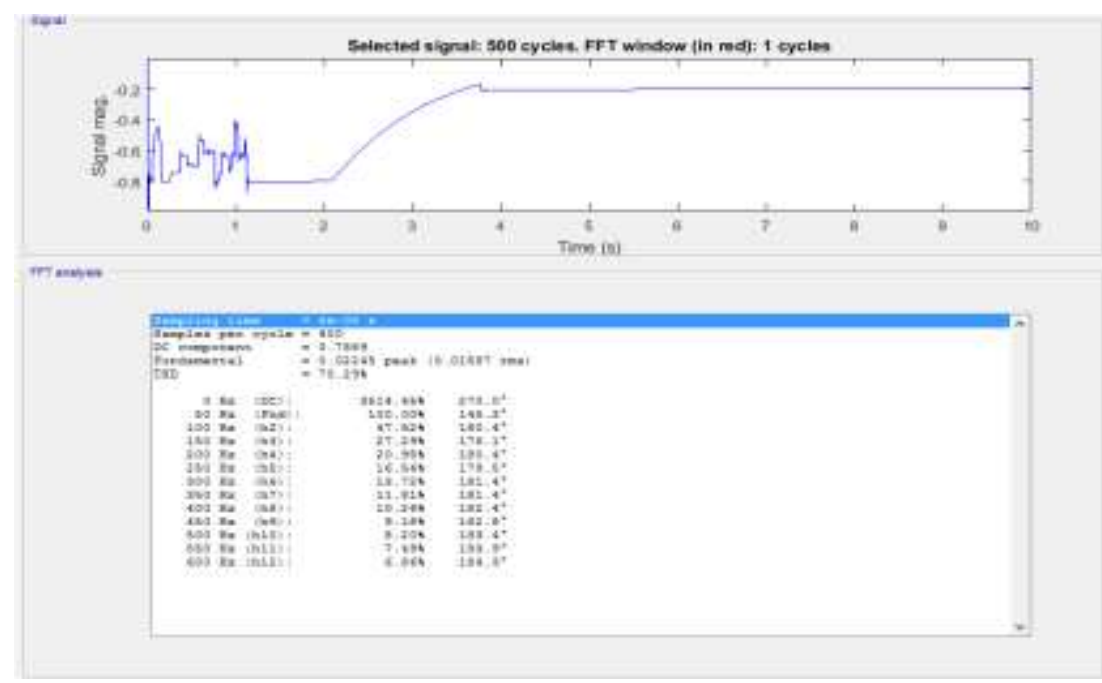

Figure 9. Power GUI FFT Analysis for PSO Technique 


\subsection{Artificial Neural Network (ANN) Technique}

A Multi- Layer Perceptrons (MLP) neural network concept is applied to map between the modulation rate and switching angles to be used further. Thus, neural network generates the appropriate switching angles for the inverter later by learning.The Modulation Index table is as shown in the Table 1 to obtain the switching angles. The load output voltage is as shown in Figure 9 with the output voltage of 200KV AC and the total harmonic distortion is $42.96 \%$ which is reduced as compared to PSO technique as tabulated in Table 2 .

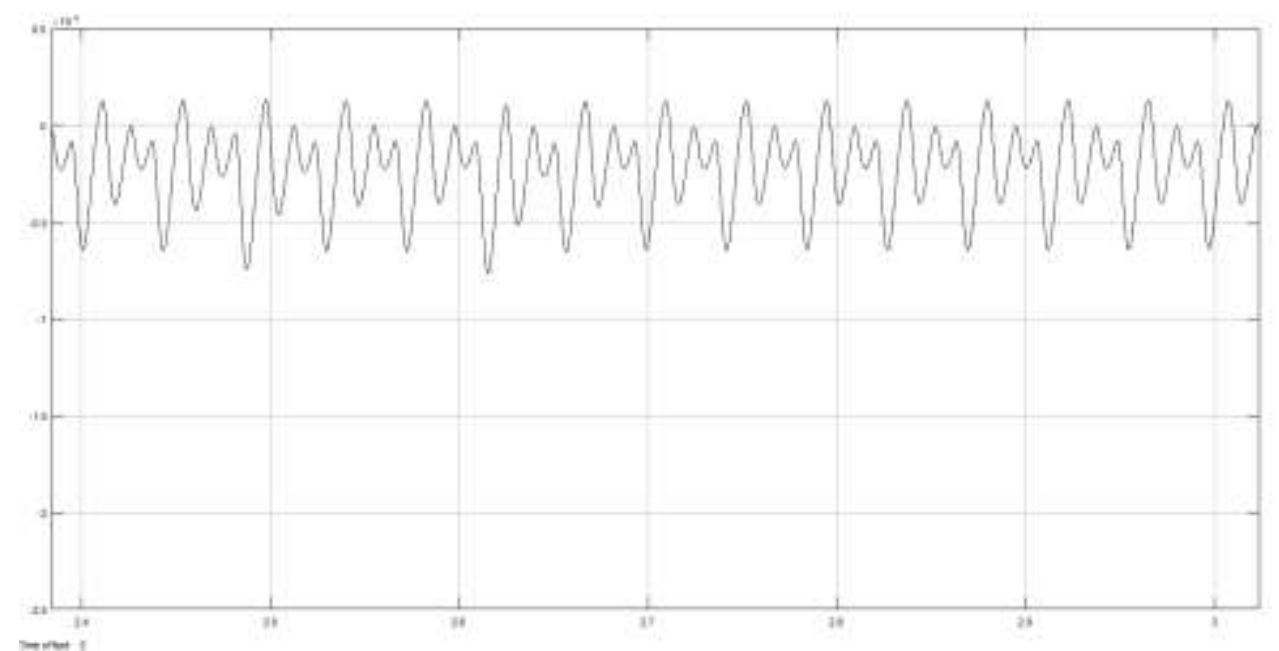

Figure 10. Load Output Voltge of ANN Technique



Figure 11. Power GUI FFT Analysis of ANN Technique

\subsection{ComparitiveAnalysis}

As discussed in [12], the comparitive analysis of the simulation of SPWM PSO -PID Technique and ANN technique for 7 level 6 switches modified cascaded $\mathrm{H}$ bridge multilevel inverter using MATLAB/Simulink system is carried out. The total harmonic distortion of the ANN technique is improved compared with the PSO-PID technique as shown in Table.2, thus can be seen that power quality of the microgrid in terms of total harmonic distortion (THD) is improved. 
Table 1. Modulation Index Table

\begin{tabular}{|c|c|c|c|c|c|c|}
\hline \multirow{2}{*}{ 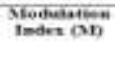 } & \multicolumn{6}{|c|}{ 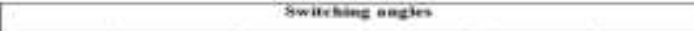 } \\
\hline & श्रिक & Wh orat & Qx (सan) & en (rad) & es $(200)$ & 26 (roth \\
\hline ठक & कonis3 & 25 & 8352 & ब्रs & $\pi$ & $\pi$ \\
\hline 6.55 & 0,1 & 0135 & काय & क्रs & 0 & 0 \\
\hline 6.7 & क.x & $0 \times 699$ & 860011 & 034 & "म & 0 \\
\hline 6.55 & 8.02 & 632 & 6338 & 0.125 & 0.012 & 0.063 \\
\hline or & 8.0132 & 03 & Iasa & 8025 & 0.043 & 0.172 \\
\hline 085 & oris & ars & orod & 219 & 0.08 & 0.01 \\
\hline 8 & 0.016 & $0 \times 75$ & 002 & 8354 & 0.021 & 0.013 \\
\hline 695 & क.0123 & 8269 & 8105 & 612 & 002 & 005 \\
\hline 1 & $0.01 \mathrm{t}$ & 03 & 129 & $\%$ & 0 & 0 \\
\hline
\end{tabular}

Table 2. Comparison of the Values of Modified Chbmli

\begin{tabular}{|l|l|}
\hline Switching Techniques & $\begin{array}{l}\text { Total Harmonic } \\
\text { Distortion }\end{array}$ \\
\hline SPWM PSO -PID & $70.29 \%$ \\
\hline ANN & $42.96 \%$ \\
\hline
\end{tabular}

\section{Conclusion}

In this paper, a design comparison analysis using MATLAB/SIMULINK of SPWM based PSO-PID and ANN techniques are carried out, the approach is suggested using 7 level 6 switches modified cascaded $\mathrm{H}$ bridge multilevel inverter. In this comparative analysis it is found that the SPWM technique is not easy compared with ANN Technique. SPWM based on PSO-PID controller and ANN techniques are used to enhance the power quality and optimize the harmonic problems for high power application systems. An approach for the computation of switching angles using artificial neural networks is seen much easier and the solutions are found better. PSO here, is used to improve approximate solutions. The trained neural network were simulated in MATLAB for online determination of the angles. As a result, total harmonic distortion is improved using ANN technique to attain the global solution by modified cascaded $\mathrm{H}$ bridge multilevel inverter.

\section{Future Scope}

The paper has limited the work to MPPT solar renewable energy source only. Many other renewable energy sources will be implemented in the future. Design of new topologies will be carried out to reduce the switches and DC sources for cascaded multilevel inverters for various voltage levels and artificial intelligent techniques will be applied for power quality improvement with grid integration.

\section{References}

[1] E. A. Bakirtzis and C. Demoulias, "Control of a microgrid supplied by renewable energy sources and storage batteries", XXth International Conference on Electrical Machines (ICEM), (2012), pp. 20532059.

[2] C. Jian, C. Yanbo and Z. Lihua, "Design and Research of Off-grid Wind-Solar Hybrid Power Generation Systems", 4th InternationalConference on Power Electronics Systems and Applications (PESA), (2011), pp. 1-5.

[3] F. Ornelas-Tellez, "Optimal Control for a Renewable-energybased Micro-grid", Special session on renewable energy ROPEC, (2014).

[4] G. Konstantinou, M.S.A. Dahidah and V.G. Agelidis, "Solution trajectories for selective harmonic elimination pulse-width modulation forseven level waveforms: analysis and implementation", IET Power Electron, vol. 5, no. 1, (2012), pp. 22-30.

[5] S. Sangita and K.U.B Vaidya, "A Comparison of two MPPT techniques for PV system in MATLAB Simulink", International Journal of engineering research and development, vol. 2, issue 7, (2012), pp. 73-79. 
[6] M. Hanif, V. Khadkikar, X. Weidong and J.L. Kirtley, "Two Degrees of Freedom Active Damping Technique for LCL Filter-Based Grid Connected PV Systems", IEEE Transactions on Industrial Electronics, vol. 61, no. ${ }^{\circ} 6,(\mathbf{2 0 1 4})$, pp. $2795-2803$.

[7] N.A. Yusof, N.M. Sapari, H. Mokhlis and J. Selvaraj, "A Comparative Study of 5-level and 7-level MultilevelInverter Connected to the Grid", international conference on power and energy,IEEE, PEcon, (2012).

[8] M. Suresh Kumar and K. Ramani, "Comparative Review of Modulation Techniques for Harmonic Minimization in Multilevel Inverter", World Academy of Science, Engineering and Technology, International Journal of Electrical, Computer, Energetic, Electronic and Communication Engineering, vol:8, no. 12, (2014), pp-1931-1938.

[9] A.R. Beig and A. Dekka, “ Experimental verification of multilevel inverter-based standalone power supply for low- voltage and lowpower applications", IET Power Electron., vol.5, no.6, (2012), pp.635643.

[10] M. S. Sivagamasundari and P. Melba Mary, "Real Time Implementation of PI and PID Controlled Cascaded H-Bridge Eleven Level Inverter using SPWM", Journal of Microelectronics, Electronic Components and Materials, vol. 46, no. 2, (2016), pp. $65-73$

[11] N. Kumar Gupta and R. Mahanty, "Harmonic Optimization of Multilevel Inverter", International Journal of Engineering Research and Development,vol. 11, issue 10, (2015), pp.28-43.

[12] M. Suresh Kumar and K. Ramani, "Comparative Review of Modulation Techniques for Harmonic Minimization in Multilevel Inverter", World Academy of Science, Engineering and Technology International Journal of Electrical, Computer, Energetic, Electronic and Communication Engineering, vol. 8, no. 12, (2014). 